\title{
Advanced Practice Nursing in Latin America and the Caribbean: seeking its implementation
}

Pilar Alejandra Espinoza Quiroz'

ORCID: 0000-0003-2533-6566

Beatriz Rosana Gonçalves de Oliveira Toso" ORCID: 0000-0001-7366-077X

'Universidad San Sebastian, Facultad de Ciencias para el Cuidado de la Salud. Santiago, Chile. "Universidade Estadual do Oeste do Paraná. Cascavel, Paraná, Brazil.

How to cite this article: Espinoza P, Toso BRGO. Advanced Practice Nursing in Latin America and the Caribbean: seeking its implementation. Rev Bras Enferm. 2021;74(Suppl 6):e74suppl601. doi: http://dx.doi.org/10.1590/0034-7167.202174suppl601
Healthcare organizations are increasingly complex and specialized, seeking to optimize their quality and safety standards, and be able to meet the growing needs of their users. To face this reality, health professionals need to adapt to respond in time to the demands of the health context. In turn, the World Health Organization (WHO), through the Global Strategy on Human Resources for Health 2030, urges countries to optimize their health performance through teamwork, collaboration, continuous training, innovation, and evidence-based practice ${ }^{(1)}$.

To answer this imperative, it is important to reflect on the evolution of nursing professionals beyond general nursing, stopping at the specialist and more recently in Advanced Practice Nursing (APN) with a master's degree; in some countries, has already advanced to the doctorate in nursing practice. It is intended that this deepening facilitates the understanding of the current state of professional development in Latin American countries, with a view to considering contextually relevant strategies that facilitate the advancement of the function and provision of care to patients/families and the community at a higher level of professional specialization. Literature on the results of the role of APN in the countries in which it was implanted reports improvement in the results of user satisfaction, cost reduction for governments, expansion of access to services and resolution of health problems, in addition to greater autonomy for nurses in their practice assistance ${ }^{(2)}$.

There are reports in scientific literature of several countries that place the role of specialist nursing since the early 1900 s and its transition or progression to APN around 1970-1980. The role of specialists emerges as a strategy to respond to the growing unmet health needs of patients and their families, with nursing taking on activities that involve learning new clinical skills that broaden the scope of their professional practice and which were little considered by doctors or responded to the lack of these professionals in health organizations ${ }^{(3)}$. This experiential learning situation evolves towards the development of training programs in the same hospitals that involve restricted theoretical content and specialized guidance, exercising this new function in their daily work. Later, these informal programs are transformed into certifications and, later, into formal programs in nursing schools ${ }^{(3)}$.

The recognition by universities of these programs and the need to provide more specific knowledge and skills for practice of each specialty have evolved, expanded and become more complex to respond to the growing needs of users and families, including new skills that have led to to the development of APN with a master's degree. Before proceeding, it is relevant to clarify the concept of APN according to the International Nursing Council (INC) in the document "Directrices en enfermería de practica avanzada 2020". INC recognizes it as the application of theoretical, practical and evidence-based treatments through a wide-ranging practice that seeks to answer patients' problems in a specific clinical area and whose core competence is the practice centered on the patient and his family, followed by expert guidance and training, patient consultation, ethical 
decision-making, collaboration, research skills and clinical and disciplinary leadership ${ }^{(4)}$.

Over the past 30 years, several countries have worked on implementing APN education programs. Currently, the emphasis is on the standardization of these programs and professional certification of APN, facilitating their mobilization and international recognition in different health environments. Although the role of APN is established in many countries and continues to expand, confusion about the role persists among nursing professionals, those from other health disciplines, those responsible for professional policy and regulation, and the general community. This confusion of roles between specialist nurses with extensive clinical experience, nurses with academic backgrounds in their specialty, and APN with a master's degree threatens to prolong the challenge of fully integrating the role of APN into health systems.

As countries, mainly in Latin America, seek to establish the role of APN in different health contexts, it is important to recognize the importance of a clear and in-depth understanding of the role and competencies of two nursing professionals to advance their transfer and implementation in the context with a clear sense of the role and functions to be played. When observing the external aspects of the profession that influence the development and implementation of APN, the local legal and regulatory aspects appear that are capable of limiting or favoring their recognition; with this, access to these specialized professionals from patients and their families to solve current care gaps, especially in Primary Health Care, where APN would use a comprehensive approach that involves the family and the community to solve the health problems that afflict them the population, especially in developing countries.

It is imperative to recognize that the status quo cannot continue and that governments need to reorient their health systems and support the implementation of APN if they are to respond effectively to health promotion, disease prevention and treatment at different levels of care, presenting as an effective and efficient resource before the challenges of accessibility, quality and safety of health care in several countries.

It is relevant to mention the mandatory mandate for nursing leaders, who must promote a shared vision of professional development that promotes cohesion and collaboration among professionals and that allows them to advance in an organized manner, supporting and negotiating as one voice in the search for the same goal; only then can APN be promoted to the community and other professional groups.

\section{REFERENCES}

1. Asamblea Mundial de la Salud. Estrategia Mundial de Recursos Humanos para la Salud. El personal de salud de aquí a 2030 [Internet]. 2016[cited 2021 Jan 15].WHA69.19 Available from: https://www.observatoriorh.org/sites/default/files/webfiles/fulltext/2015/reu_rhs_sept_ arg/estrategia_global_rhs_oms.pdf

2. Laurant M, van der Biezen M, Wijers N, Watananirun K, Kontopantelis E, van Vught AJ. Nurses as substitutes for doctors in primary care. Cochrane Database System Rev. 2018;7:CD001271. doi: 10.1002/14651858.CD001271.pub3

3. Hanson CM, Hamric AB. Reflections on the continuing evolution of advanced practice nursing, Nurs Outlook, 2003;51(5):203-211. doi: 10.1016/S0029-6554(03)00158-1

4. Consejo Internacional de Enfermería. Directrices de enfermería de practica avanzada [Internet]. 2020[cited 2021 Jan 15]. Available from: https://www.2020yearofthenurse.org/uploads/2020/04/ICN_APN-Report_ES_WEB.pdf 